\title{
Coulisses
}

Revue de théâtre

8 | Eté 1993

Varia

\section{Théâtre Universitaire de Iasi}

\section{(2) OpenEdition}

1 Journals

Édition électronique

URL : http://journals.openedition.org/coulisses/2555

DOI : $10.4000 /$ coulisses.2555

ISSN : 2546-9460

Éditeur

Presses universitaires de Franche-Comté

Édition imprimée

Date de publication : 1 juillet 1993

Pagination : 22-23

ISSN : 1150-594X

\section{Référence électronique}

«Théâtre Universitaire de lasi », Coulisses [En ligne], 8 | Eté 1993, mis en ligne le 15 mars 2019 ,

consulté le 24 octobre 2019. URL : http://journals.openedition.org/coulisses/2555 ; DOI : 10.4000/ coulisses. 2555

Ce document a été généré automatiquement le 24 octobre 2019.

Coulisses 


\section{Théâtre Universitaire de Iasi}

\section{Le metteur en scène}

\section{Irina Popescu}

16-01-1963

Irina Popescu a fait ses études à l'Institut d'Art Théâtral et Cinématographique « I.L. Caragiale » de Bucarest. Elle travaille actuellement en tant que metteur en scène professionnel au Théâtre National de Iasi. Pour sa première mise en scène en 1989 (Six personnages en quête d'un auteur de Luigi Pirandello), elle reçoit le prix UNITER décerné par l'Union Théâtrale de Roumanie. Depuis, chaque année, elle met en scène plusieurs pièces qu'elle choisit dans le répertoire mondial: Pirandello, Giraudoux, Tchekov, Garcia Lorca, Tenessee Williams, Carlo Gozzi,... Depuis 1990, elle collabore en permanence avec le Théâtre Universitaire de Iasi, la compagnie « Pluriel ». 


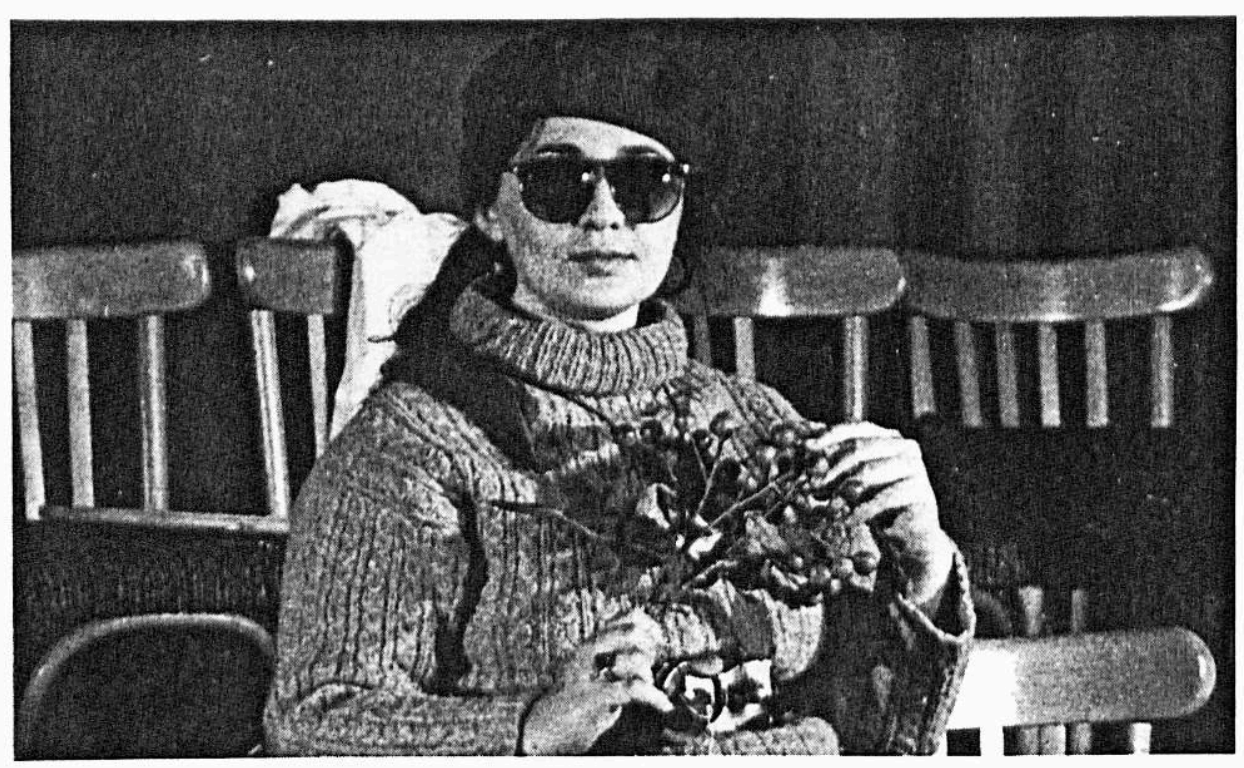

\section{Son point de vue}

2 Pour les membres de la troupe "Pluriel», être partie prenante du projet Cymbeline, c'est d'abord une aventure; une aventure fascinante car l'essentiel, c'est le désir de rencontrer d'autres troupes venant d'autres pays et appartenant à d'autres cultures, à une autre spiritualité. En ce qui concerne précisément la pièce et notre approche, nous nous intéressons surtout à mettre en relief l'idée de solidarité et d'unité européenne. C'est pour cela que nous avons choisi les trois premières scènes du III ème acte (quand Cymbeline défend l'indépendance de la Bretagne face à Rome, quand Pisanio refuse de sacrifier Imogène). Ces scènes, qui permettent en outre de faire jouer un grand nombre d'acteurs, expriment l'idée de résistance contre l'agression, quelle que soit sa forme. Elles montrent également comment peut s'établir, dans certaines circonstances, cette rencontre entre des individus, entre des intérêts particuliers, qui donnera naissance à ce phénomène complexe et si difficile à réaliser qu'est la solidarité.

\section{Les étudiants sur scène}

\section{Cristina BAZU}

Rodica Liliana CORA

Victor Sébastian costACHE

Dragos MUSAT

IUlia PAVAL

Octavian Gabriel POPARDA

Tudor PETREUS

Ilinca Domnita TARANU

Andreea Silvana SZALONTAY

Scénographie : Rodica PORUMBEL 


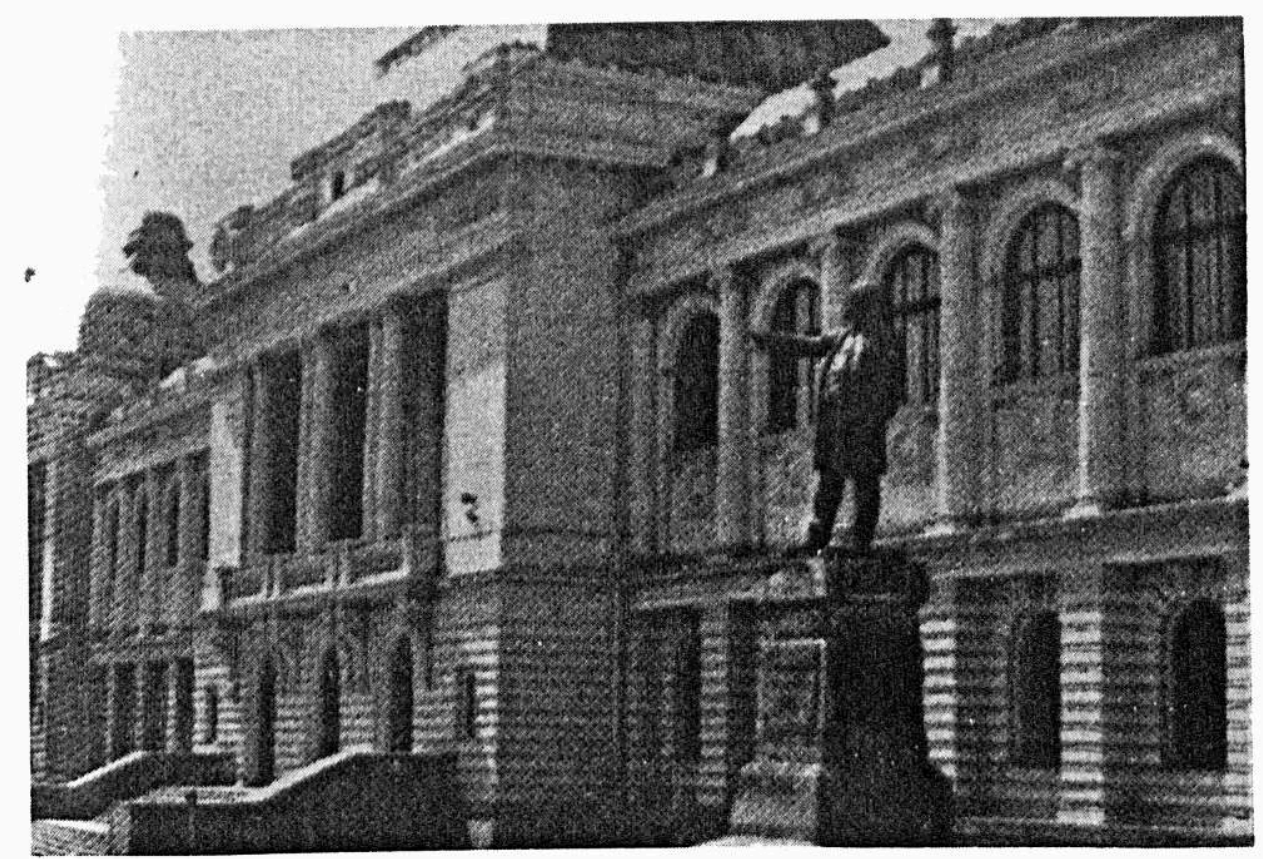

\section{Le T.U.}

3 L'Université Alexandru Ioan Cuza de Iasi a été fondée en 1860 par Cuza, le premier prince régnant des Principautés Roumaines réunies (1859) - date qui équivaut à la naissance de la Roumanie moderne. C'est le plus ancien établissement roumain d'enseignement supérieur. Iasi, capitale traditionnelle de la Moldavie, a toujours été un foyer important de culture. L'Université de Iasi s'est progressivement développée ; environ 10000 étudiants y font actuellement leurs études dans ses nombreuses facultés : droit, lettres, sciences, ...

4 La Moldavie étant une région très francophile et francophone, le département de français est très important. Il a été dirigé pendant de longues années par un professeur de prestige, grand ami de la France, Nicolas Popa, spécialiste de l'œuvre de Nerval, bien connu en France.

5 Le Théâtre Universitaire de Iasi a été fondé en 1990 immédiatement après les événements de décembre 1989 lorsqu'il est devenu possible de renouer avec les liens traditionnels d'amitié avec la France. Le groupe «Pluriel» est une troupe formée d'étudiants en lettres, mais aussi en médecine et en sciences. Ils ne jouent qu'en français. Leur répertoire est composé de pièces roumaines traduites en français, de pièces françaises ou de pièces de dramaturges roumains d'expression française tels Eugène Ionesco ou Georges Astalos. La compagnie «Pluriel » s'est déjà fait connaître sur la scène internationale puisqu'elle s'est produit deux années consécutives au festival de théâtre étudiant «Fous de théâtre » à Avignon $(90,91)$ et au festival «Les Tombées de la Nuit » à Rennes (91). 